\title{
FLUTING AND FACETING OF ROCK FRAGMENTS
}

\author{
JOHN H. MAXSON \\ Balch Graduate School of the Geological Sciences \\ California Institute of Technology \\ Pasadena, California \\ Contribution No. 302
}

Reprinted for private circulation from

The Journal of Geology, Vol. XLVIII, No. 7, October-November 1940 PRINTED IN THE U.S.A. 


\title{
FLUTING AND FACETING OF ROCK FRAGMENTS
}

\author{
JOHN H. MAXSON
}

Balch Graduate School of the Geological Sciences

California Institute of Technology

Pasadena, California

Contribution No. 302

Reprinted for private circulation from

The Journal of Geology, Vol. XLVIII, No. 7, October-November 1940

PRINTED IN THE U.S.A. 


\title{
FLUTING AND FACETING OF ROCK FRAGMENTS
}

\author{
JOHN H. MAXSON \\ California Institute of Technology
}

\begin{abstract}
Rock surfaces are eroded by particle-laden currents of air and water so that under given conditions polishing, grooving, and fluting result. Polish is characteristic when the particles are fine and when abrasion predominates over solution in removal of material. Grooving and fluting in homogeneous rocks are caused by the more or less regular variation in abrasive intensity resulting from vortical movement of the fluid. When the vortices are shed from points of separation of flow from the rock surface, it seems that grooves elongate in the current direction may be cut. Under some conditions the vortices appear to be fixed in position and discontinuous flutes are cut. The stream flutes and wind flutes which have been observed are similar in form although the stream flutes are between fifteen and twenty times larger.

Under certain conditions fragments are faceted in particle-laden currents. Facets at high angles toward the current tend to be worn off uniformly and polished, while those inclined at low angles are cut by the most characteristic flutes and grooves.

Limestone fragments partially imbedded in alluvium may be faceted by solution during rain wash. Moisture driven by rain commonly produces solution effects consisting of an anastomosing and rugose system of ridges and rills on nearly horizontal surfaces and of deflected streamlike rills on steep-side and lee surfaces.

In erosion of limestone fragments by particle-laden air currents abrasion is dominant over solution. Rilled surfaces tend to be smoothed and polished. However, it is believed that all the various types of polish, fluting, grooving, faceting, and rilling may develop essentially simultaneously in one locality, presumably during the time span of a few tens of years The predominance of one feature or another depends upon the idiosyncrasies of the immediate neighborhood of the limestone fragment.
\end{abstract}

\section{INTRODUCTION}

The erosion of immobile rock surfaces in currents of air or water has often been noted by geologists. The cutting power of these currents is implemented by fine-rock particles in suspension, and the effective process has therefore been described as abrasion. Continued operation on stones produces fluting, faceting, and polishing. Solution plays a role whose importance is difficult to analyze because of the masking or dominating effect of abrasion, the more soluble rocks likewise being softer. Where there is no directed current, exposed soluble surfaces are irregularly etched and stones protruding from soil are faceted by rain wash.

The two processes, solution and abrasion, together or separately, produce analogous grooving and fluting in the surfaces of isolated stones, which may or may not be combined with faceting. The mechanics involved in a directed current are those governing turbulent 
and vortical flow. In rain wash, water films are sometimes so thin and velocities so low that the flow is essentially laminar.

In streams with small suspended load and low velocity, channel cutting is accomplished by the abrasive action of rolling and sliding tools and by solution. The channel form tends to be smooth and regular. With high velocity and small suspended load the vortical movement of the water causes pothole erosion. Under certain conditions elongate depressions may be cut in the channel in the direction of the current. When the depressions are long and continuous, they may advantageously be termed "grooves." Under conditions of high velocity and large suspended load a variety of cut forms are developed on the channel itself and on the larger tools - not only potholes and grooves but also short and discontinuous depressions which are herein defined as flutes. The use of "flute" in this restricted sense geologically in distinction from "groove" is not incompatible with some specialized established uses, i.e., "in decorative art, a concave depression relatively long and of any form, the sides not necessarily parallel" (Century Dictionary). As the result of removal of material from the upstream face of boulders during fluting, facets are developed.

Faceting of stones occurs under subaerial conditions through solution of exposed protuberances or through abrasion by wind-borne sand, this process sometimes being supplemented by solution by wind-blown rain. In wind-faceting, wind-fluting may occur, the form of the flute being similar to that developed in a stream of water because both result from vortical movement of the particle-laden fluids.

SCULPTURE OF ROCK FRAGMENTS BY STREAM EROSION STREAM-FLUTING

Stream-grooving and potholing on bedrock and boulders are common features of high-gradient streams. Stream-fluting, however, occurs most prominently in a stream of high velocity that also has a high content of suspended matter. An excellent example of streamfluting in the Grand Canyon is figured and described by G. K. Gilbert:

Nothing can resist the incessant impact of the fine siliceous particles, and the whole river bottom, including both solid rock and boulders, bears indisputable testimony to the mightiness of their work. Every exposed surface is polished 
at least, and the most salient faces are deeply and beautifully carved. Plate X gives an example of this sculpture, in which the material wrought is a homogeneous, fine-grained limestone . . . . and the curved face lay nearly horizontal. . . . The concave facets, of which the surface is composed, appear to be of the nature of paraboloids of revolution, the apices of which are turned upstream. ${ }^{\mathrm{I}}$

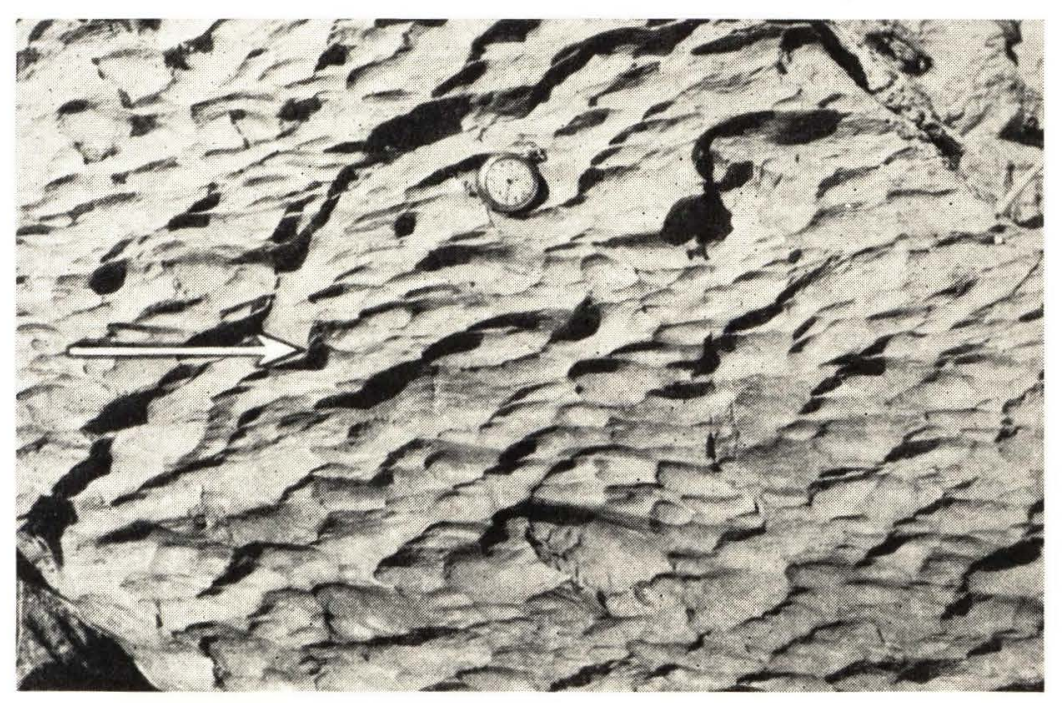

Fig. r.- Stream-fluted limestone boulder at irg Mile Rapids, Grand Canyon, Arizona. The current moved from left to right. Note the elongation of the flutes in the direction of flow and the sharp overhanging lip frequently occurring on the upstream margin.

Lugeon has described stream-fluting in the Yadkin River of North Carolina. ${ }^{2}$ He emphasized the analogy between this type of fluviatile erosion and eolian erosion.

Stream-fluting and the reduction of both bedrock and boulders in the Colorado River have later been described in more detail. ${ }^{3}$ Although the flutes are most commonly found on limestone boulders

I "Report on the Geology of Portions of Nevada, Utah, California, and Arizona," U.S. Geog. Surv. West of the Iooth Meridian, Vol. III (1875), p. 72.

${ }^{2}$ M. Lugeon, "Le Striage du lit fluvial," Annales de geographie, Vol. XXIV (IgI5), pp. $385^{-9}$.

${ }^{3}$ John H. Maxson and Ian Campbell, "Stream Fluting and Stream Erosion," Jour. Geol., Vol. XLIII, No. 7 (1935), pp. 729-44. 
in the deltas of the tributary streams, they also have been found on both boulders and bedrock of granite, pegmatite, schist, and basalt in the main river channel. Their occurrence on the insoluble rocks suggests that abrasion by water-borne silt particles has played a predominant role and that relative hardness, not solubility, determines the frequency and extent of development. It may be supposed,
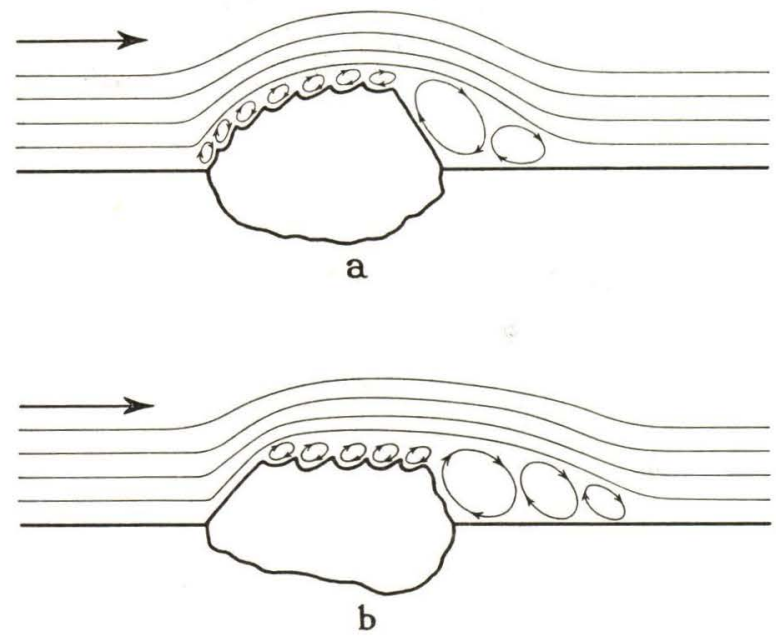

Fig. 2.-(a) Flow about an obstacle with upstream face at low angle to current direction showing vortices which might be developed thereon by skin friction. Pattern is intended primarily to represent water flow. (b) Flow about an obstacle with steep upstream face and point of separation with generation of vortices as a wake phenomenon. Under most conditions the vortices break away and move downstream. However, the erosion of flutes testifies to some stability under the natural conditions encountered. The vortex pattern is believed possible under proper conditions in either air or water. (Neither sketch is drawn to scale.)

however, that solution plays some part in the removal of material from limestone boulders.

The form of the flutes is determined by vortices formed by turbulent flow along large more or less flat surfaces and by disturbance of flow about irregularities of all types. The vortex axes tend to be subparallel to the water-rock boundary under conditions of uniform flow as along relatively flat bedrock surfaces or about the boulder section transverse to the general current as suggested in Figures I and 2. On the upstream area of boulders or other obstructions the 
axes may be inclined at higher angles to the rock surfaces. Large vortices with slower rotation occur below the obstruction and are relatively ineffective in abrading the downstream surface. Examination of fluted surfaces, such as that shown in Figure I, suggests that vortices of varying axial angle with the rock surface are present. Some flutes have spiral markings, others longitudinal markings, and still others are smooth throughout, indicating difference in the position of eddy rotation. Many of the flutes appear to be mutually interfering and encroaching. The extremely complicated and variable vortex pattern is probably due to change in river velocities passing from one flood stage to another.

\section{STREAM-FACETING}

The result of the differential removal of material from the upstream face of a boulder is faceting, the production of a rough face inclined at an angle of $50^{\circ}$ or less to the direction of the impinging current. Faceting in streams is not a very common phenomenon because the condition of steady and rapid silt-laden stream flow not split by boulders is rare.

Stream-faceted pebbles in the bed of the Breede River, South Africa, have been described by Taljaard. ${ }^{4}$ The faceted pebbles were observed to be

restricted to the flanks of the main current where infrequent hollows or none occur, and where the depth of the water does not exceed 8 inches. .... Large boulders showing crude faceting on upstream faces are found at greater depths, but only where they directly face an unhampered floor- or bed-current, and are, in addition, encircled by sand.

This paper also notes that the better-shaped pebbles are those occupying the more stable positions either on a tenacious bottom or wedged in place.

A few examples of faceted limestone boulders have been observed in the Grand Canyon. Figure 3 shows a homogeneous, fine-textured limestone boulder from the upstream face of which considerable material has been removed. This face is rough but, in a general way, is inclined upstream at an average angle of about $50^{\circ}$. There

${ }^{4}$ M. S. Taljaard, "Note on the Occurrence of Faceted Pebbles as Products of Stream Flow," Trans. Geol. Soc. South Africa, Vol. XLII (1939), pp. I9-2 I. 
is no evidence from the shape of the boulder as a whole that jointing is responsible for the face. The base is large, broadly rounded, and securely wedged among the other boulders of the delta. The boulders illustrated in Figure 4 occur on a bar and are less securely held in place. However, the upstream face of the limestone boulder is, neglecting surface irregularities and some curvature, inclined about

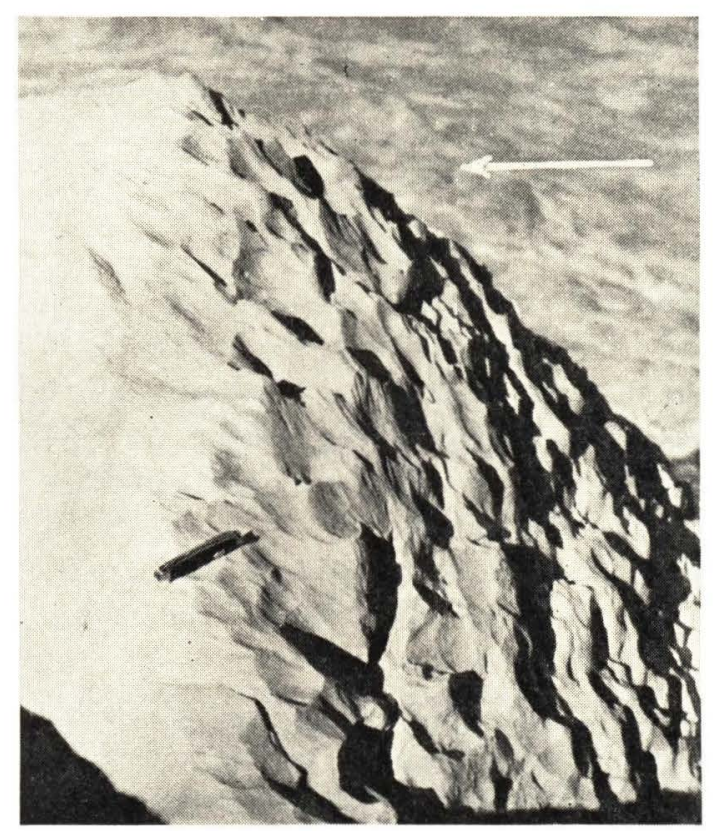

FIG. 3.- - Limestone boulder with fluted and faceted upstream face. Arrow shows direction of flow of the Colorado River. Delta of Hermit Creek, Grand Canyon, Arizona. (Photo by Ian Campbell.)

$40^{\circ}$ upstream. The downstream face shows no scouring action and is intersected by the upstream face at an acute angle. The schist boulder in the foreground of Figure 4 shows strong evidence of abrasion on the upstream surfaces which are inclined about $45^{\circ}$ and $30^{\circ}$, respectively. The schistosity is truncated by the $30^{\circ}$ surface, and a few well-developed flutes are present. The bases of the boulders are large and irregular, and no suggestion of an imbricated or "shingle" structure"is present. 
RATE OF FACETING

No quantitative data on rate of faceting during stream-fluting have been obtained. General considerations, the probable stability of boulders during the seasonal floods, and the development of flutes on freshly exposed joint surfaces suggest that the process of abrasion in the Colorado River is very rapid. Flutes seem to have been formed

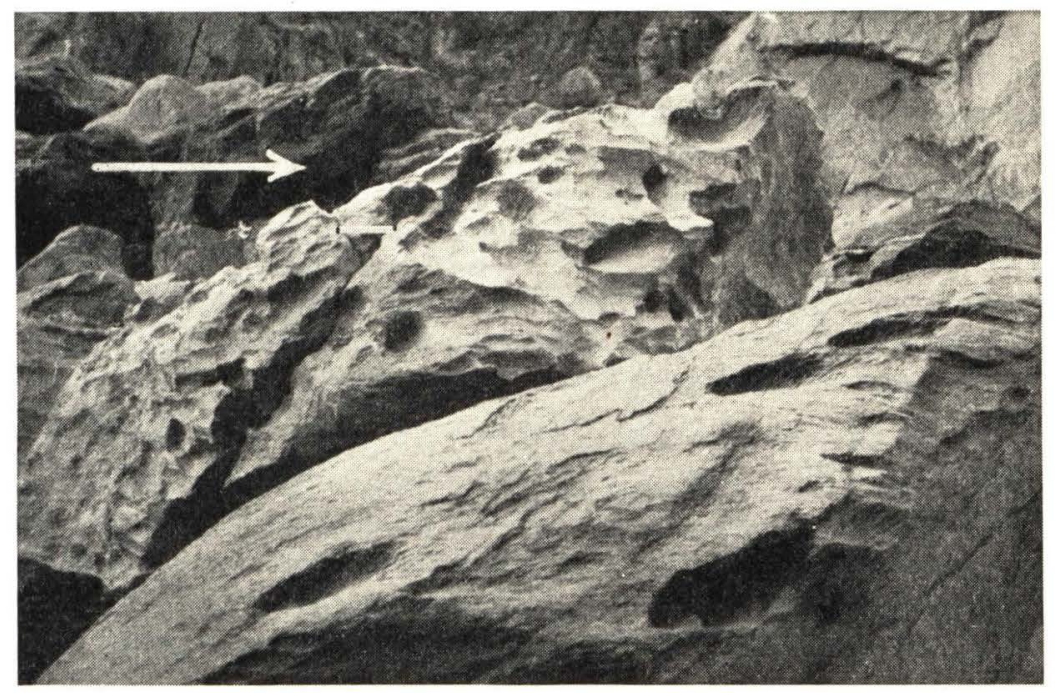

FIG. 4.-Fluted and faceted boulders; in front, boulder of quartz mica schist truncated across schistosity; in back, homogeneous limestone boulder. A six-inch scale rests on the limestone below the point of the arrow indicating current direction. Colorado River opposite the mouth of Trinity Creek, Grand Canyon, Arizona.

during such a short time as several years, and considerable reduction in situ or faceting probably occurs in a few tens of years.

\section{SCULPTURE OF ROCK FRAGMENTS BY SUBAERIAL EROSION}

\section{WIND EROSION}

The general features of wind erosion have long been known and described. The effects of wind-borne sand abrasion on large surfaces have been noted as pitted, etched, engraved, fluted, and grooved. Polish may be developed independently on smooth surfaces or may, in some cases, be formed on the fluted surfaces. Rock fragments are reduced in place and faceted. Illustrations of fluting on large 
surfaces will be cited, and the occurrence of flutes on small faceted fragments will be discussed with reference to conditions of formation and mechanism of origin.

Blake described the forms produced by winds confined in San Gorgonio Pass between the San Bernardino and San Jacinto mountains of Southern California.

The effects produced on the vertical surfaces of the rock exposed to the wind were, perhaps, the most curious and interesting, for here the hard minerals were left standing out in points, the softer feldspar being cut away on all sides. Masses of feldspar and quartz thus presented very rough and uneven surfaces.

Where the feldspar was charged with small garnets, and was directly in front of the wind, a very peculiar result was produced; the garnets were left standing in relief, mounted on the ends of long pedicles of feldspar which had been protected from abrasion under the garnets while the surrounding parts were cut away. These pointed masses or needles of feldspar, tipped with garnets, stood out from the body of the rock in horizontal lines, pointing like jeweled fingers, in the direction of the prevailing wind. 5

Gilbert likewise observed excellent examples of wind work.

Blake and Newberry observed that in the Colorado Desert the pebbles were etched by drifting sand, and our examinations have detected the same phenomena in the Gila and Amargosa deserts, and other broad valleys. The most perfect work of this character that has fallen under my observation, is on a broad gravel mesa sloping gently toward the Colorado River, just below the mouth of the Virgin. The surface of compacted sand and gravel is hard, smooth, and even, and upon it are thickly strewn loose pebbles, shaped by the drifting sand. Hard, homogeneous stones, as quartzite and chalcedony, are rounded and highly polished, as though by collision in running water; crystalline rocks, as basalt and trachyte, are unevenly worn, the harder crystals maintaining prominences; the limestones are carved, with a network of vermicular grooves, into the most beautiful arabesque designs (Plate IX) ${ }^{6}$

The faceted cobbles shown in his Plate IX appear to have the typical vermiculated surface. They were formed by solution and modified by abrasion. Referring to a locality on Fortification Hill near Boulder Dam, Gilbert states:

Boulders of basalt and trachyte, gradually weathering from the gravel of which the hill consists, are here subjected to a natural sand-blast of great

5 W. P. Blake, in Report of Explorations in California for Railroad Routes, etc. ("Pacific Railroad Reports," Vol. V [Washington, D.C.: War Department, I857]), Part II, p. 92.

${ }^{6} \mathrm{Op}$. cit., p. 83 . 
power. The wind, confined by the hills, has locally but two directions-directions exactly opposed to each other-and these are conspicuously portrayed by the carving. In the larger of the basalt boulders represented in the illustration (Plate VIII), a point near the left margin faces the prevailing wind, and from it eroded grooves radiate over the convex surface; and the course of the blast, as it whirls around its edge, is finely shown on the stone at the right. ${ }^{7}$

These boulders split the wind. The sculpture described is analogous to the radiating flutes formed on boulders in a swift silt-laden stream. A pitted and fluted granite boulder near Garnet Station (Blake's occurrence) is figured by Blackwelder and ascribed to abrasion by wind-borne sand. ${ }^{8}$

An excellent example of wind-fluted limestone at Um Shersher, south of Kharga Oasis, Egypt, is figured by Hume. ${ }^{9}$ These flutes are extremely elongate and presumably were cut under higher wind velocities than those described below from Death Valley.

Brunhes has described eolian potholes in rocks of the Nubian Desert. ${ }^{10}$ These are 4-8 cm. in diameter and 6-10 $\mathrm{cm}$. in depth. They occur most often on more or less vertical faces either facing the prevailing wind or facing away from it. Corrosion pits are also found in the same locality. Because some of the early pothole forms are of irregular orientation while better-developed forms are definitely oriented in the wind direction, Fleury believes that these developed as corrosion pits and were later modified by eolian corrasion. ${ }^{\mathrm{II}}$ Some of the potholes have been opened longitudinally and subjected to rectilinear friction.

Fleury described in detail the minor wind erosional forms he observed in Portugal. Grooved and fluted surfaces were attributed to two factors; one petrographic, which is concerned with the differential erosion of hard and soft parts of rocks; the other topographic, that is, direction of erosional processes by the accidental pattern

${ }^{7}$ Ibid., p. 84 .

${ }^{8}$ Eliot Blackwelder, "Cavernous Rock Surfaces of the Desert," Amer. Jour. Sci., Vol. XVII (5th ser.; 1929), p. 396.

${ }^{9}$ W. F. Hume, "The Egyptian Wilderness," Geog. Jour., Vol. LVIII (I92I), p. 252.

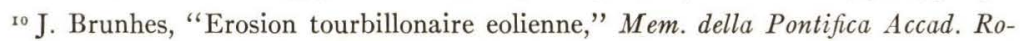
mana dei nuovi lincei, Vol. XXI (1903), pp. I29-48.

${ }^{\text {Ir }}$ Ernest Fleury, "Formes de desagregation et d'usure en Portugal," Mem. Soc. Port. Sci. Nat., geol. ser., No. I (1919). 
of the surface. In his interpretation the grooves are paths cut by means of rectilinear friction by the canalized sand between ridges. The ridges, themselves, would be miniature jardangs.

Boulders which split the wind and have elongate, radial grooves are illustrated by Fleury in his Figure 42. His fluted pebble (Fig. 52) closely resembles types found at the Death Valley locality described

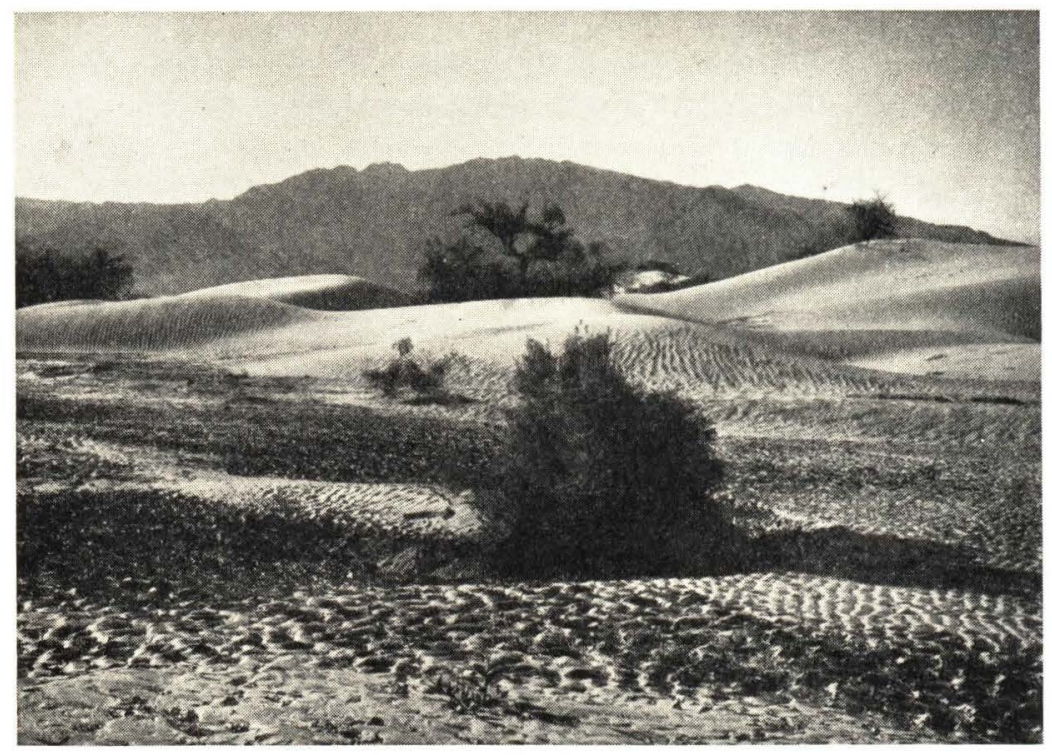

Fig. 5.-View looking southwesterly over the sand dunes of Death Valley. The dune ripple marks indicate a prevailing southeast-northwest wind. The sands have been deposited about mesquite trees. In the foreground is the wash of Salt Creek, an ephemeral stream flowing from right to left. A number of properly oriented ventifacts were found in this wash.

below. Fleury notes that this type of grooving is found on horizontal or slightly inclined surfaces and is similar to stream-abraded grooves.

\section{WIND-FLUTING IN DEATH VALLEY}

The writer has observed wind-fluted and wind-faceted limestone cobbles and pebbles with polished quartzite cobbles and rilled limestone fragments in association near Stovepipe Wells and Salt Creek in the northern part of Death Valley, California. The ventifact lo- 
cality is on the northeast side of Death Valley on the Boundary Canyon alluvial fan. The average annual rainfall at Furnace Creek Ranch, several miles south, is 1.4 inches. The general trend of the Death Valley graben is northwest-southeast, and a constriction in valley width just south of the ventifact locality is provided by Tucki Mountain of the Panamint Range. The wind tends to be confined to a northwest-southeast direction. The writer has personally observed a moderate wind from northwest to southeast in the evening and a strong wind from southeast to northwest in the morning during the month of December. Under some conditions the wind velocities may approximate those of a gale. Thus the ventifact locality is characterized by regular strong winds blowing from two opposing directions. With a low and intermittent rainfall, alluvial fragments may be relatively stable for several seasons. Hence, with an ample supply of fine debris available for tools, the locality is ideal for wind abrasion and wind-faceting. Three aspects of subaerial erosion of rock fragments are well exemplified. These are windfluting, wind-faceting, and rilling.

Freshly carved wind flutes are found only on limestone surfaces, horizontal or inclined at low angle in the direction of the prevailing wind. More or less modified and partly obliterated flutes may exist on other faces as the result of successive rotations. Quartzite faces and limestone faces inclined at high angle to the direction of the wind are smoothly polished. Most of the limestones which are fluted are homogeneous, and no suggestion of compositional or textural control for the location of hollows is present. It is believed, therefore, that wind flutes are cut beneath vortices by fine sand. The vortex, with its higher-velocity air current, is the locus of the more active abrasion.

The flutes are small, oval-shaped scallops elongate in the general wind direction. Typical examples are illustrated in Figures 6, 7, and 8. They are easily distinguished from stream flutes shown in Figure I by much smaller size (average length $\frac{1}{4}$ inch as compared with 4 inches), relatively much shallower depth, and less tendency to be overhung on the up-current end. Some flutes are elongate, and there are gradational types culminating in rather long, continuous grooves. 
Inasmuch as the flutes are cut by impact and abrasion of sand grains beneath vortices, a fairly stable vortex pattern is indicated. The grooves, on the other hand, suggest vortices descending along the rock surface in the wind direction. For this reason the writer believes that the cutting of the grooves is dependent on the vortex pattern and not on canalization of sand between ridges, as suggested

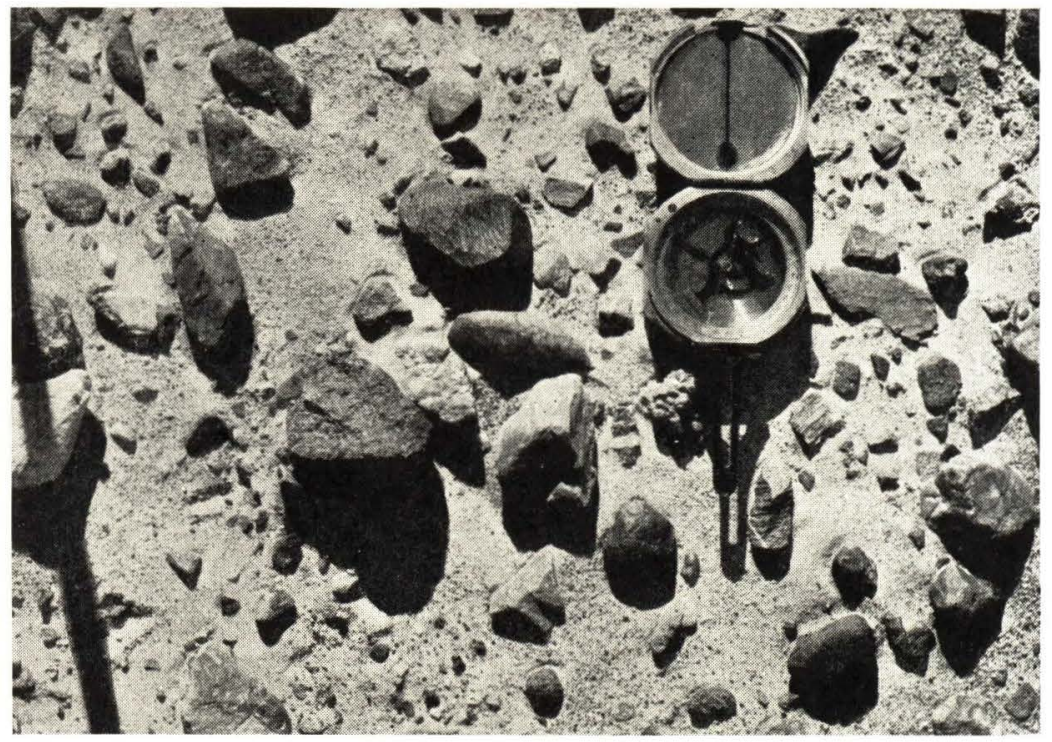

Fig. 6.-Undisturbed terrace surface showing limestone cobble with upper surface sharply wind fluted and faceted about $\mathrm{I}$ inch above and parallel to the ground level. Quartzite fragments show some rounding of corners and polish but are otherwise little eroded. The top of the photograph is south, and the prevailing wind blows from the southeast (upper left) to the northwest (lower right) in the general direction of the elongation of the flutes.

by Fleury. Once formed, the grooves may be modified by sweeping sand currents at air velocities below those critical in the generation of vortices.

\section{MECHANICS OF FLUTE FORMATION}

The flow pattern of fluids may, at higher velocities and under irregular channel or boundary conditions, become extremely complicated. Mathematical and empirical studies of turbulence under ideal conditions are still in part dependent on statistical analysis. 
The theory of turbulent flow is the subject of intensive contemporary hydraulic and aerodynamic research. The flow of fluids in extremely complex natural channels under varying physical conditions,

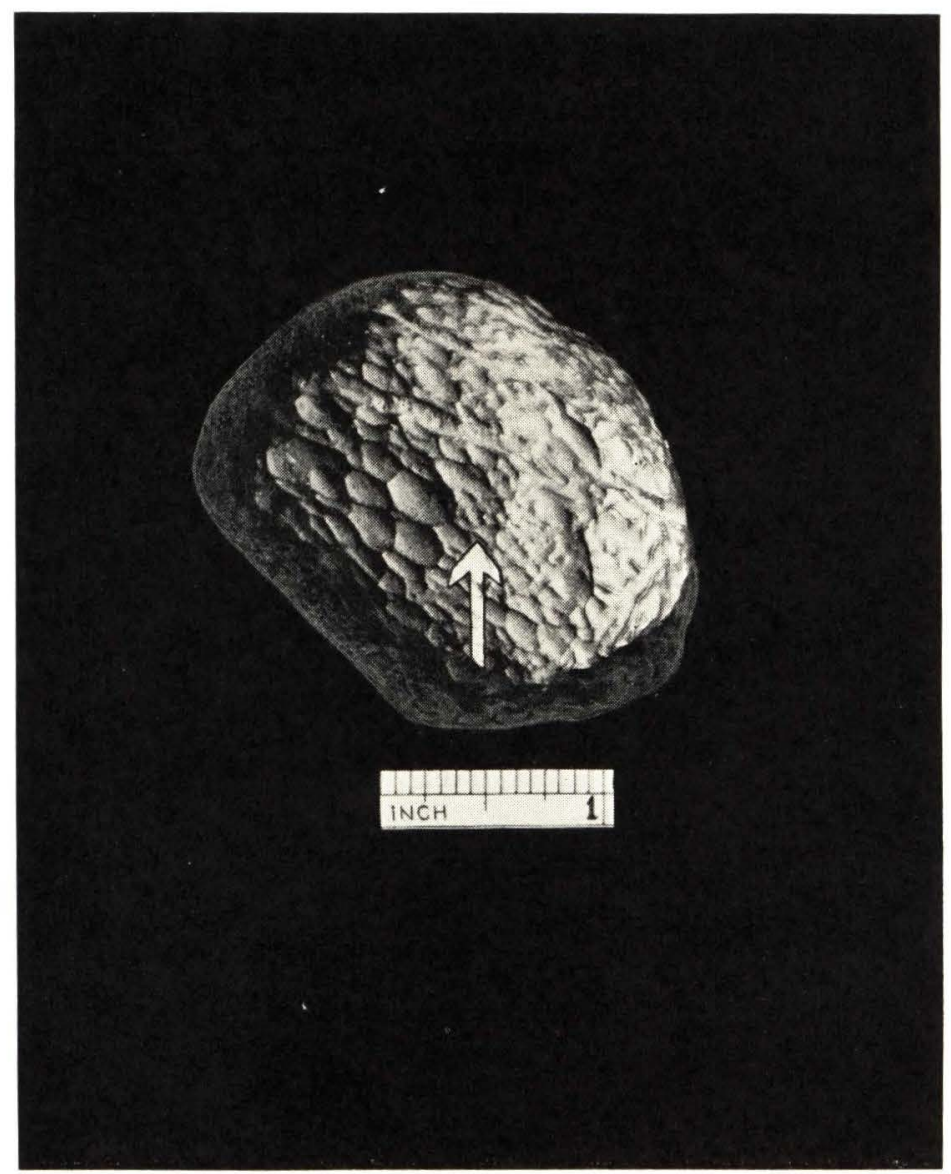

FIG. 7- - Strongly fluted horizontal facet. Arrow indicates north. Winds blow from lower right to upper left.

therefore, cannot as yet be analyzed rigorously. Nevertheless, consideration of the principles of fluid mechanics will assist in the understanding of the processes of erosion and rock forms resulting therefrom in currents of air and water.

There are three groups of variables which affect the flow of air 
and water: (I) linear dimensions which describe the geometrical proportions, as, for example, in the case of an obstacle, the diameter $d$; (2) the dynamic characteristics of flow as the mean velocity $V$; and (3) the properties of the fluid with respect to weight, viscosity, surface tension, and elasticity. A generally used dimensionless parameter is the Reynolds number, $R=(V d / \gamma)$, where $\gamma$ is the kine-

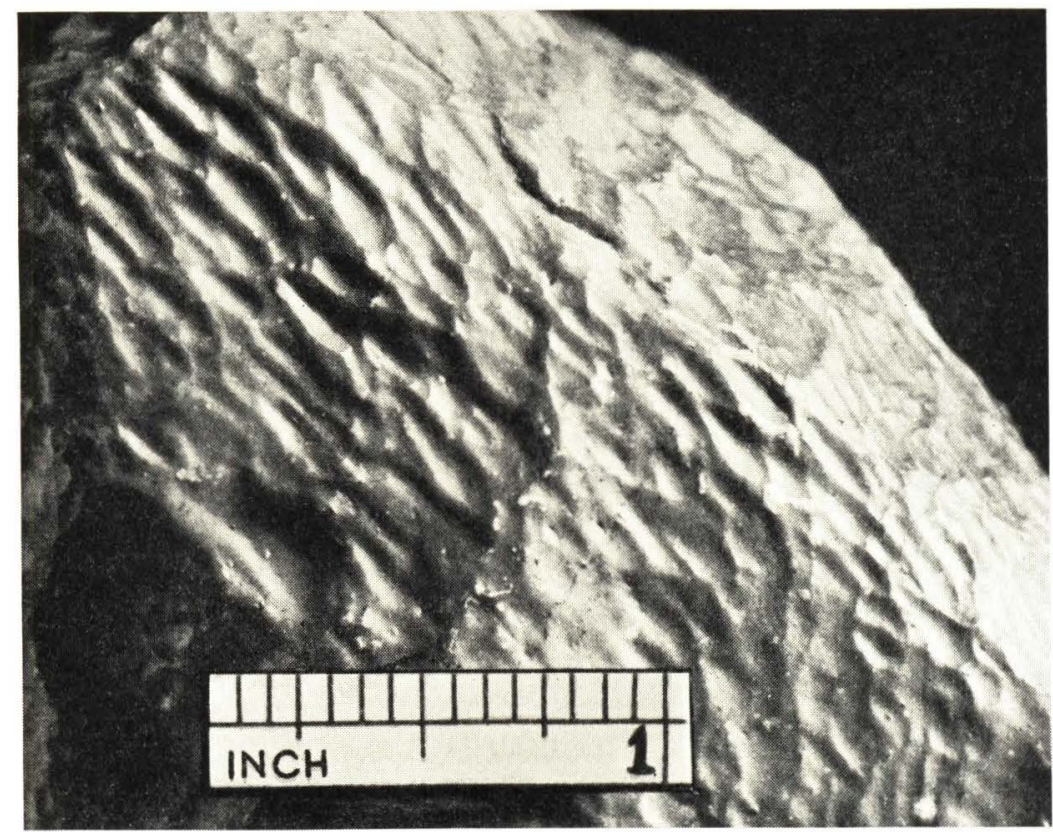

Fig. 8.-Wind-fluted limestone cobble surface, Death Valley. Flute shapes resemble those of stream flutes in Fig. I, except that there is no overhanging lip. The wind swept from southeast (lower right) to northwest (upper left).

matic viscosity. The behavior of flow can be designated on a continuous scale of Reynolds numbers.

Streamline or laminar flow near a flat boundary involves the regular movement of a fluid without any local fluctuation in velocity, i.e., movement in layers without vortices wherein the layer at the boundary has a forward velocity of zero and those outward have successively higher forward velocities, the greatest increase taking place in the layers of fluid next to the boundary. In general, laminar 
flow occurs only when the Reynolds number is very low because all disturbances are effectively damped by viscous action. Even considerable geometrical irregularities in boundary may not suffice to initiate vortices. However, with increasing values of $R$ (increased velocity), disturbances are readily set up too great to be damped by viscous shear. At intermediate values of $R$ along a nonangular boundary vorticity is confined to the boundary layer. Obstructions or curves in the confining channel (on the solid boundary) are causes of vorticity in some cases. In flow about a body where the curvature exceeds a certain critical value, vortices develop at what is known as the point of separation, i.e., where the streamlines leave the bounding surface and vortex sheets form the boundary layer. Vortices are then shed downstream, forming a wake. The vortices introduce a complex pattern of secondary motion in the fluid. In turbulent flow, masses of fluid are constantly changing position within the fluid body and are brought into regions of different velocity. The pattern of vorticity is usually illustrated by that developed about obstacles perpendicular to the flow. Such an obstacle generates vortex layers from each side known as vortex pairs which form the wake.

The mechanism of the motion may be explained in terms of the boundary layer and vortex layers. Separating the fluid in the wake from the main flow are the vortex layers which left the surface at the positions of separation. At moderately small Reynolds numbers the vortex layers, originating on the two sides of the body, come together farther downstream. Vorticity diffuses from the layers into the main body of the fluid, but is also generated in the boundary layer and added to the vortex pair. At small Reynolds numbers a state of equilibrium is set up between the rates of generation and the diffusion of vorticity, and the vortex pair is stationary relative to the solid body. As the Reynolds number is raised the rate of generation of vorticity increases; in order to counteract this the vortex layers become longer in the direction of flow, so as to provide a larger area from which vorticity can diffuse; at the same time the strength of the individual vortices in the vortex pair increases. The vortex layers are unstable; at some limiting Reynolds number they break away from the solid body and the vortices travel downstream. ${ }^{12}$

With increase to high Reynolds numbers the intensity of the vortices becomes greater, and they are more elongate in the direction

${ }_{12}$ Modern Development in Fluid Mechanics, ed. S. Goldstein (London: Oxford University Press, 1938), p. $55^{2}$. 
of flow. Likewise the higher the Reynolds number, the closer the vortices are formed to the point of separation.

Application of the foregoing principles to the practical cases of stream-fluting and wind-fluting is beset with difficulties. In the present state of our knowledge no rigorous application may be made. On any given surface in nature many irregularities of form may exist, and the velocity of air or of water flow is subject to irregular variation. However, by making certain assumptions, we may compute the Reynolds numbers for air under possible conditions at the Death Valley ventifact locality and for water in the Colorado River.

$\begin{array}{lll} & \begin{array}{c}\text { Kinematic viscosity of air at } \\ 59^{\circ} \mathrm{F} \text { at sea-level (effect of } \\ \text { suspended matter neglected) }\end{array} & \gamma=\frac{\mathrm{I}}{6380} \\ \text { Height of fragment } & d=\mathrm{I} \text { inch } \\ R=23,39 \mathrm{I} & V=44 \mathrm{ft} . / \mathrm{sec} . \\ & \begin{array}{l}\text { Velocity (30 miles per hr.) } \\ \text { Kinematic viscosity of water } \\ \text { at } 50^{\circ} \mathrm{F} \text { (effect of suspended } \\ \text { matter neglected) }\end{array} & \gamma=\frac{\mathrm{I}}{70800} \\ & \begin{array}{l}\text { Height of fragment } \\ \text { Velocity (7.5 miles per hour) }\end{array} & d=\mathrm{I} \text { foot } \\ R=778,800 & & \end{array}$

A Reynolds number of $2 \times 10^{4}$ is high and $7 \times 10^{5}$ is very high. In both cases the flow is turbulent. It has been noted that the size of stream flutes on midstream boulders is on the average sixteen times greater than wind flutes. Stream flutes on some channel walls in regions of lower stream velocity are noticeably smaller than those found on midstream boulder deltas. Thus it would appear that the size of the vortices is related to the Reynolds number. The lack of correspondence in magnitudes (flutes twenty times greater produced with Reynolds number one hundred times greater) may be due to the approximate nature of the Reynolds numbers used. For the computation in the Colorado channel a value of velocity, $V$, was taken from the mean velocity in the total cross section during flood, whereas the velocity decreases greatly toward the channel walls. The Reynolds number in the vicinity of submerged boulders must 
be much lower than the figure given. Variation in the nature of the suspended load introduces another unknown factor.

The distribution of stream flutes on channel surfaces and on the upstream faces of boulders suggests that vortices induced by skin friction are responsible. Minor surface irregularities (roughness) doubtless complicate the pattern. The flutes on boulder peripheries across the direction of flow (i.e., rock surfaces downstream from a shoulder and upstream from another abrupt curve) appear to show some regularity in spacing and size as though formed in vortex trains below points of separation. Formation as a wake phenomenon is also suggested by the confined occurrence of flutes on the periphery of a lava boulder found near Lava Falls below the first points of separation. No flutes are formed on the downstream face, owing to diffusion of energy from vortex layers into the stream.

The regular distribution of stream flutes is noteworthy, inasmuch as vortices are believed to be shed from the point of separation above critical Reynolds numbers. Presumably the flow in the Colorado River must have a value conducive to stability of position. Once formed, the flutes may themselves have the effect of fixing vortices. One might expect the vortices to show some change in distribution and size in response to varying conditions of river flow. Such a change doubtless occurs. A theoretical distribution of flow lines about a boulder immersed in a stream of water is shown in Figure 2, $a$.

Wind-fluting has been observed so far only on horizontal facets and on surfaces inclined at low angles to the wind. The sides show no signs of concurrent fluting, although older fluting cut in a former position may be present. In the fluted fragments studied there has been a shoulder upwind from the flutes. This suggests that the wind flutes are a wake phenomenon formed in a vortex train below a line of separation. This suggestion is utilized in showing flow lines of air about an obstacle in Figure 2, $b$. If the shoulder were rectilinear and oriented at right angles to the wind, it would be expected on theoretical grounds that the vortex sheets would erode parallel troughs simulating ripplemark elongated transverse to wind direction. The actual pattern is one of many individual flutes sometimes showing a rough transverse distribution.

In both air and water the differentiation of vortex sheets into 
regions of greater and less velocity of rotation, sometimes a little offset from one another, seems difficult to explain. However, the rough periodicity of occurrence (shown to greater or less degreeless in Fig. I) would indicate that the individual flutes are formed in a regular system of vorticity. The grooves sometimes observed on the Death Valley ventifacts but not on the Colorado River boulders appear to be formed when the vortices are not stable but descend downwind from the shoulder of separation.

Unlike the stream flutes formed under flood conditions in a confined channel wherein consistently high velocities are maintained, the wind flutes are formed in fluid not confined by definite lateral boundaries and in which great and rapid fluctuations in velocity may take place. It is difficult to understand how vortices, sufficiently stable to erode flutes in solid rock, could be formed under such conditions. Possibly the fluting proceeds only in the upper range of velocities, and a set of flutes once formed may influence location of vortices under moderately variable velocities.

Questions regarding the vortex and flute pattern and its stability must await further experimental work. Additional discussion at this time is not justified by the laboratory and field data available.

WIND-FACETING

The subject of wind-faceting has been reviewed by Bryan, ${ }^{13}$ a nomenclature set up, and a bibliography of 258 titles presented. Bryan has briefly summarized the development of the theory.

The formation of facets on stones by the wear of wind-driven sand was correctly analyzed by Woodworth in 1894 . He held that the effectiveness of the sand blast as shown by Tilghman is greatest on surfaces between $30^{\circ}$ and $60^{\circ}$ from the horizontal. A facet is formed at right angles to the wind and once attaining an angle of $30^{\circ}$ is thereafter only slowly modified. Other facets are produced in shifting or overturn of stones. The formation of stones by two contrary winds as held by Travers, Enys and Mickwitz is entirely feasible but only one wind is required. Bather (rgoo) in his admirable review follows Woodworth, but continental geologists have usually followed Heim who believes that the wind splits on the edges (Kanter). ${ }^{14}$

${ }^{13}$ Kirk Bryan, "Wind-worn Stones or Ventifacts - a Discussion and Bibliography," Rept. Committee on Sedimentation for I929-30, Natl. Res. Coun. Circ. No. 98 (1931).

${ }^{14}$ " Reviews of Papers on the Geomorphology of North America, I933-35," Zeit. fïr Geomorphology, Vol. VIII (1935), p. 5 . 
Schoewe has shown experimentally that ridge-shaped ventifacts oriented at right angles to the wind can be formed by constant winds irrespective of the shape of the base of the model and that the rate of abrasion on faces sloping $30^{\circ}$ is about one-third as great as on faces inclined at angles of $60^{\circ} .{ }^{15}$ It was suggested by Schoewe that

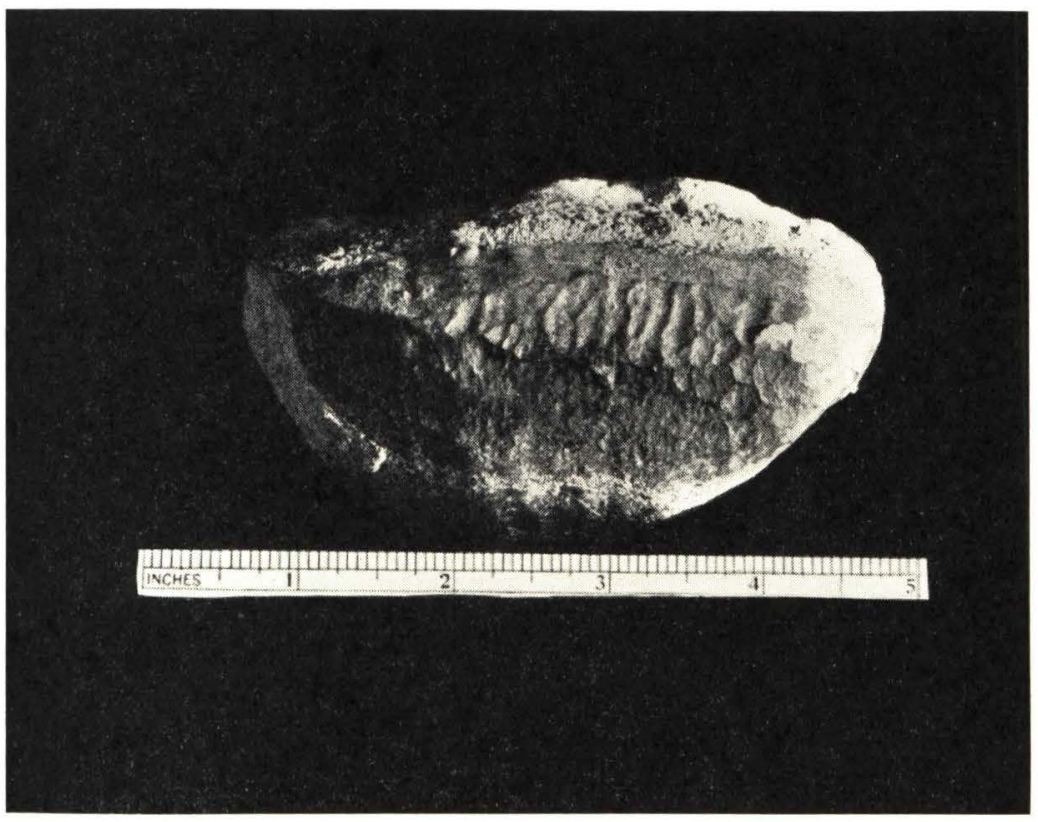

Fig. 9.-Top view of a ridge-shaped limestone ventifact from Death Valley. In its original position the long axis was northeast-southwest perpendicular to the prevailing wind directions. Opposing facets inclined at $25^{\circ}$ to the horizontal and fluted. The soil line is shown by sand grains lightly cemented to the cobble by lime.

in order to be faceted the ratio of height of the model to the height of the sand-laden current should not exceed $\mathrm{I}: 8$. In a sand stream extending to 24 inches above the ground the largest fragment faceted would have a height of about 3 inches. Larger fragments would split the wind. This generalization is supported by observations in Death Valley, where the faceted fragments have a height of less than 3

${ }^{15}$ Walter H. Schoewe, "Experiments on the Formation of Wind-faceted Pebbles," Amer. Jour. Sci., Vol. XXIV (5th ser.; I932), pp. III-34. 
inches above the ground. Larger fragments are in many cases vermiculated, grooved, and polished, but they are not faceted.

The faceted fragments at the Death Valley locality are usually composed of limestone or highly calcareous shale. The most common type is ridge shaped, with a well-developed face to the southeast and a less well-developed face to the northwest. The ridge is

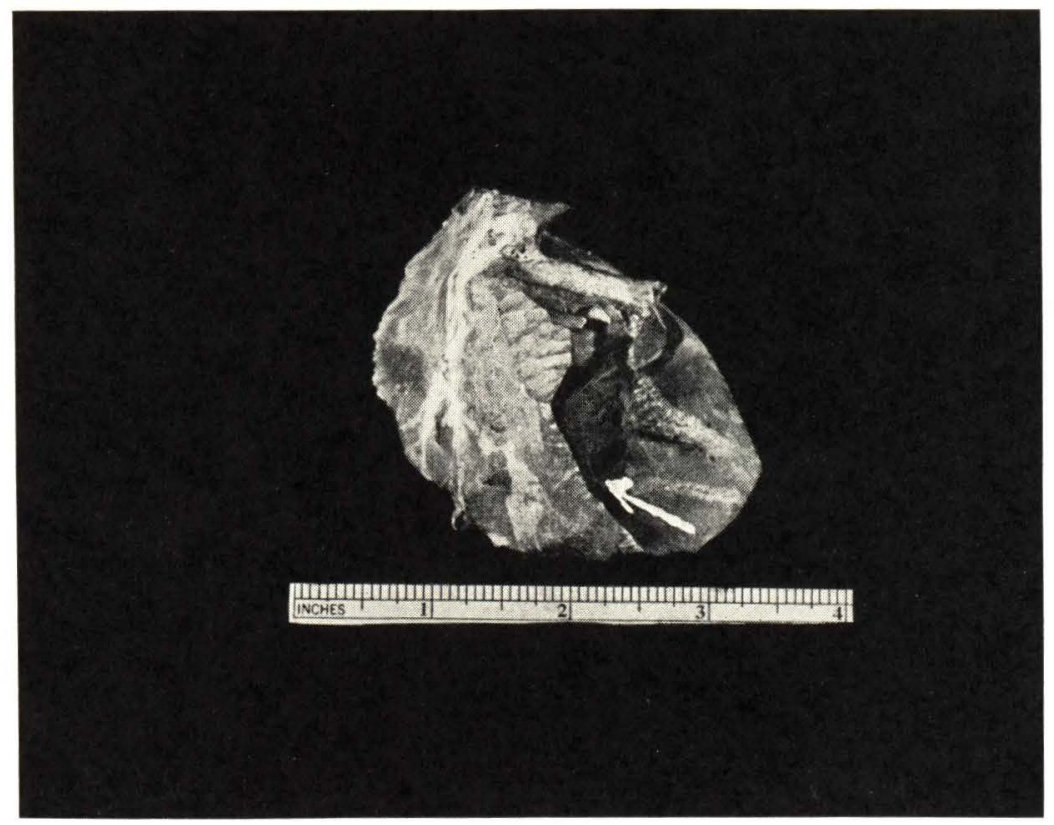

Fig. I0.-Faceted limestone cobble showing horizontal fluted facet and spurs facing principal wind direction.

oriented in a large majority of cases at right angles to the wind, checking with the observations of Wade in the Nubian Desert. ${ }^{\mathrm{I}}$ Wade noted between three and four hundred ventifacts, of which 78 per cent were set at approximately right angles to the wind and 22 per cent were set approximately parallel to the wind.

Figure 9 shows an example. The ridge was oriented at right angles to the direction of the wind. The cut faces are inclined at $25^{\circ}$ to the

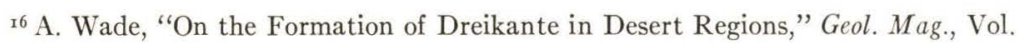
VII (I9ro), pp. 394-98. 
horizontal and do not extend evenly to the soil level. The facets presumably formed intermittently under the action of opposite winds. Faint flutes are developed on both facets. The lightly ce-

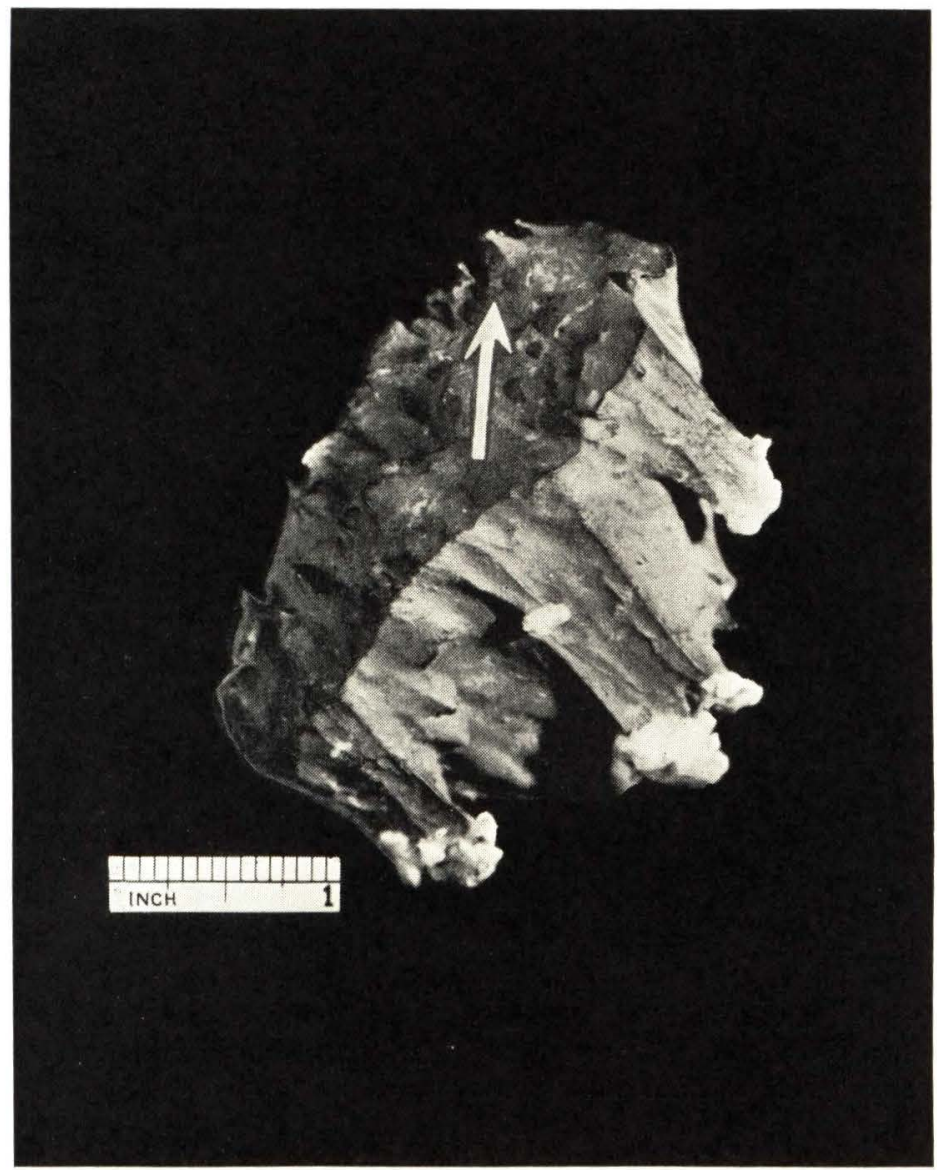

FIG. I I.-Etching of spurred facets on impure limestone. Spur tips supported by resistant silica nodules. Strongest of the opposing winds blew southeast to northwest (lower right to upper left).

mented sand adhering around the soil line offers the suggestion that to some degree solution may supplement the predominant abrasion in reducing the exposed surface. Other examples of ridge-shaped ventifacts are shown in Figures io and II. In Figure ro the oppo- 
site facets are inclined $50^{\circ}$ to the horizontal, and the ridge is truncated by a small horizontal, faintly fluted facet. Calcite veins have exercised little control on the sculpture, but minute siliceous bodies and veinlets have supported projections from the facets. Figure i I shows the striking development of pedicles of limestone pointed by silica nodules facing the prevailing winds in a manner recalling Blake's description.

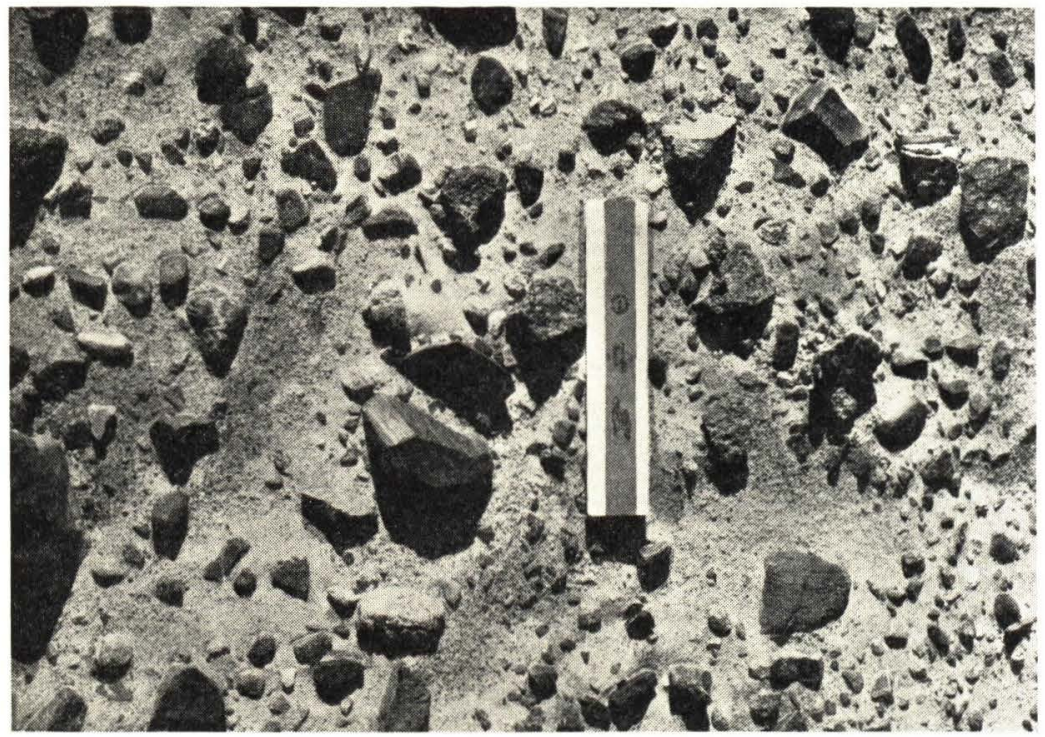

FIG. I 2.- Typical litter on alluvial surface in the vicinity of the sand dunes, Death Valley. Note limestone fragment in lower left of center with top truncated parallel to and about 2 inches above the soil surface. In the upper right corner is another horizontally faceted pebble with fluted surface. The upper end of the 6-inch scale points south. Wind direction is from upper left to lower right.

Gradation in the facet angle with the horizontal from $50^{\circ}$ (rare) through $25^{\circ}$ (common) to $0^{\circ}$ (rare) is noted. A few of the horizontal facets were reduced to, or almost to, the soil level, but many were found $\mathrm{I}$ or 2 inches above this level. The high-angle facets in homogeneous limestone were observed for the most part to be smooth and polished. The low-angle facets were observed to be fluted and polished. Figure I 2 illustrates a limestone pebble with a horizontal facet carved with faint southeast-northwest flutes. Figure 6 shows 
another example with well-defined, oriented flutes on the horizontal facet.

The rare occurrence of horizontal facets brings up the question of whether these may have been developed in situ or formed in some other position, either at a higher soil level since excavated or at an angle to the wind and later rotated. No cases of horizontal faceting are on record. Flutes, however, may be developed on horizontal surfaces. Areas of several square yards of a horizontal limestone bedding plane were found stream-fluted in the Marble Canyon of the Colorado River. A flat surface such as a joint plane, therefore, might conceivably be fluted by sand abrasion if near the ground level. However, some irregularity in the boundary between the air and the rock fragment may help to initiate the generation of vortices. Hence it seems difficult to eliminate the possibility of having the fluting proceed on a more or less horizontal surface above the general ground level. If the cutting of flutes occurs in this position, then at least some faceting likewise takes place in this position.

\section{SOLUTION-FACETING}

The importance of abrasion of rock surfaces by wind-borne sand in the cutting of facets is easily recognized, but the role of solution in facet-cutting is sometimes difficult to evaluate. Only in an environment where there is no strong and prevailing wind may the effects of solution alone be analyzed. It is, therefore, worth while to examine the conditions under which solution-faceting occurs and under which the features are formed.

The development of flat faces on portions of limestone fragments exposed above the land surface has been described by $\operatorname{Udden}^{17}$ and by Bryan. ${ }^{18}$ Udden ascribed the flattening of the pebbles to the solvent action of rain water. He considered that the flattening required a long time because the pebbles had been turned over many times. Bryan described in detail the various forms of faceted pebbles. The lime dissolved from the exposed surface was shown to be deposited as travertine on the pebble below the soil surface. The

${ }^{17}$ J. A. Udden, "The Flattening of Limestone Gravel Boulders by Solution," Geol. Soc. Amer. Bull., Vol. XXV (1914), pp. 66-68.

${ }^{18}$ Kirk Bryan, "Solution-facetted Limestone Pebbles," Amer. Jour. Sci, Vol. XVIII (5th ser.; 1929), pp. 193-208. 
travertine, resisting solution more than the original limestone, was shown to form a rim during later stages of faceting. The exposed surface, at first hemispherical, was later reduced to a low surface with a prominence or boss near the center.

Solution-faceting of this general type has been observed by the author on the Coconino Plateau and on the Tonto Platform in the Grand Canyon district. On the Coconino Plateau many fragments of the dense, gray Kaibab limestone (Permian) are found to be

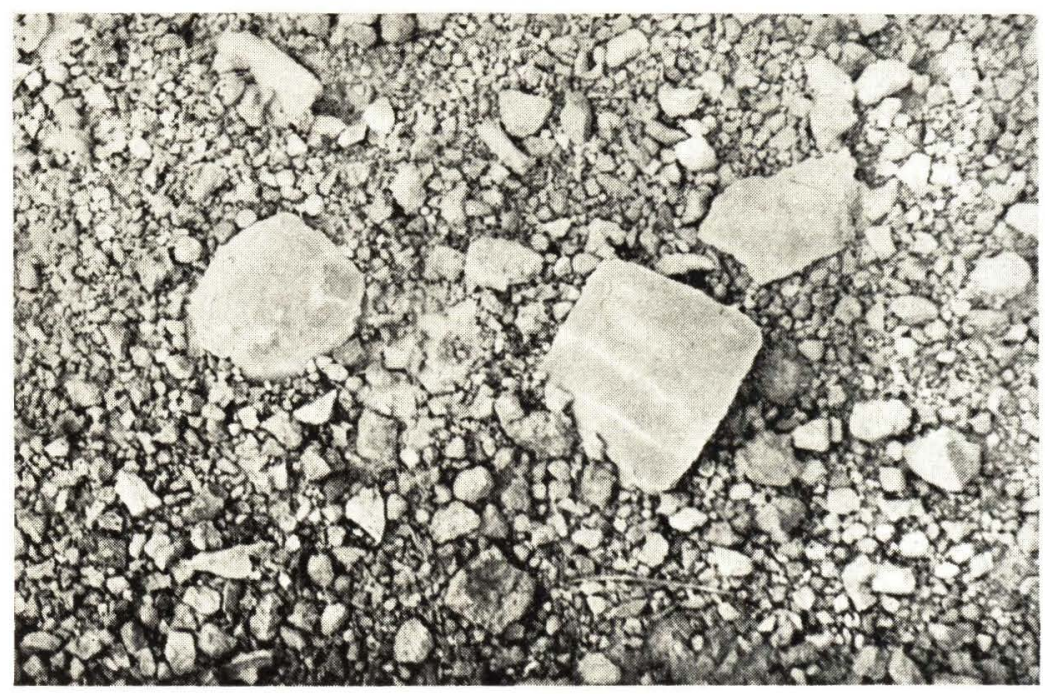

FIG. I3.-Faceted limestone fragments in situ, surrounded by small sandstone and shale fragments. The largest limestone facet is approximately 4 inches square.

faceted with rounded or hemispherical exposed surfaces. On the Tonto Platform fragments of dense, white Redwall limestone (Mississippian) are occasionally found faceted, and fragments of the soft, sandy Muav limestone (Cambrian) are faceted in large numbers. The various forms illustrated by Bryan are found. However, the geomorphic environment is not the same. Bryan's specimens occurred on a plain in Montana and on gravel terraces in New Mexico. Udden's occurrence was on Pleistocene terraces of the lower Rio Grande in Texas. The Tonto Platform cannot be regarded as old as or as stable as any of these surfaces. It is a sloping bench 
cut in soft Bright Angel shales (Cambrian), controlled by the more resistant, cliff-forming, underlying Tapeats sandstone (Cambrian). The platform is drained by numerous small stream courses which are occupied intermittently during rainy seasons. The faceted fragments lie embedded in a gravelly soil (Fig. I3) on the interfluves. Some occur on slopes of $5^{\circ}-10^{\circ}$, but on the steeper slopes disturbance by

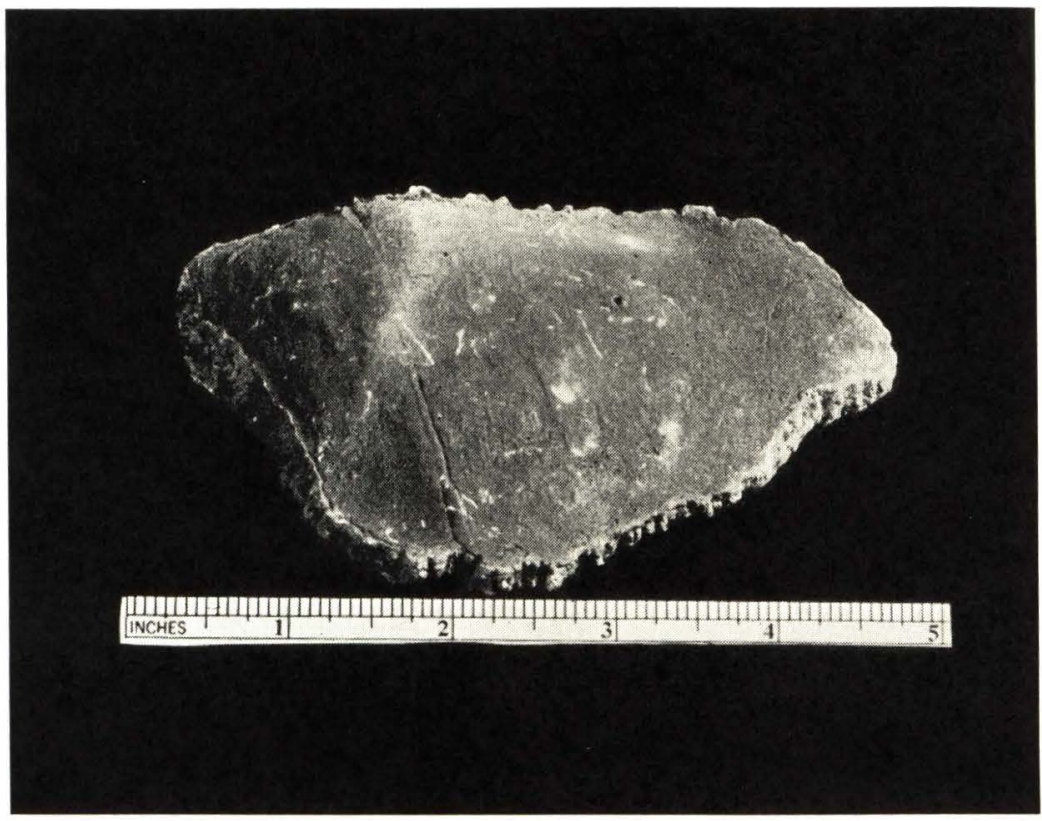

FIG. I4.-Limestone fragment solution-faceted on upper and lower surfaces. Tonto Platform.

creep is rapid, and solution-fretted, but not faceted, fragments are more common.

As pointed out by Bryan, the central boss is more prominent on some pebbles than others, and his explanation that this provides a slope down which water may flow appears likely. The natural corollary of this is that a larger amount of water passes over the peripheral area of the face, thereby dissolving more limestone than at the center. This action would tend to maintain convexity. All the larger facets found on the Tonto Platform possessed some central convex- 
ity. Only some smaller and possibly more porous fragments have nearly flat or actually concave facets. In these cases the margins of the face were supported by the rim, and removal by solution was more or less uniform over the whole surface or was actually greater in the center. Figure I4 shows a thin limestone fragment which has evidently been beveled on its lower surface, then turned over and beveled on its upper surface. Figure I5 shows a typical solution-

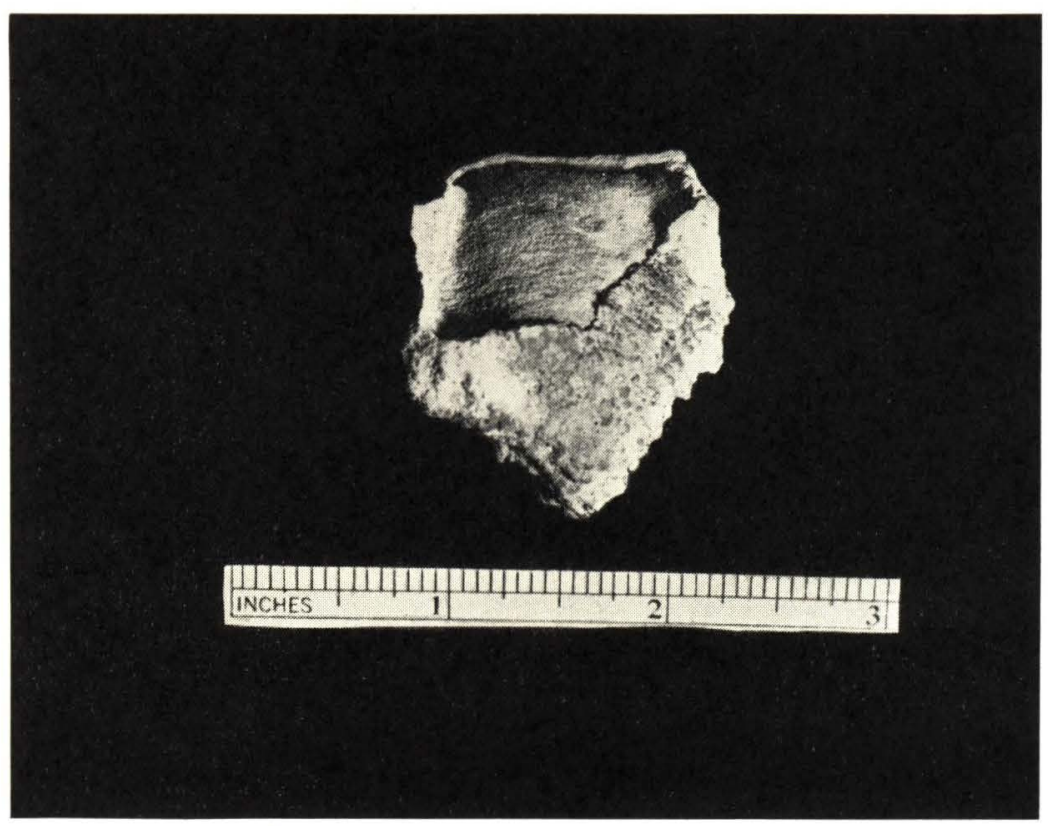

FIG. I5.- Solution-faceted limestone fragment showing characteristic central boss, travertine rim, and travertine deposited on lower surface. Tonto Platform.

faceted fragment with one face. About its irregular bottom is a heavy deposit of travertine.

Likewise recorded by Bryan is a variable amount of the secondary calcite in different occurrences. In some cases the lack of travertine may indicate an incipient stage of faceting. However, on the Tonto Platform the fragments lacking travertine were found to lie on the steeper slopes where one might expect the rain solution to be readily conducted away either down the surface or through the soil. Figure 
I6 shows such a fragment. Only a slight amount of secondary calcite has been deposited on the undersurface. On the exposed face several rills occur which follow fine fracture planes. Some of these etchings

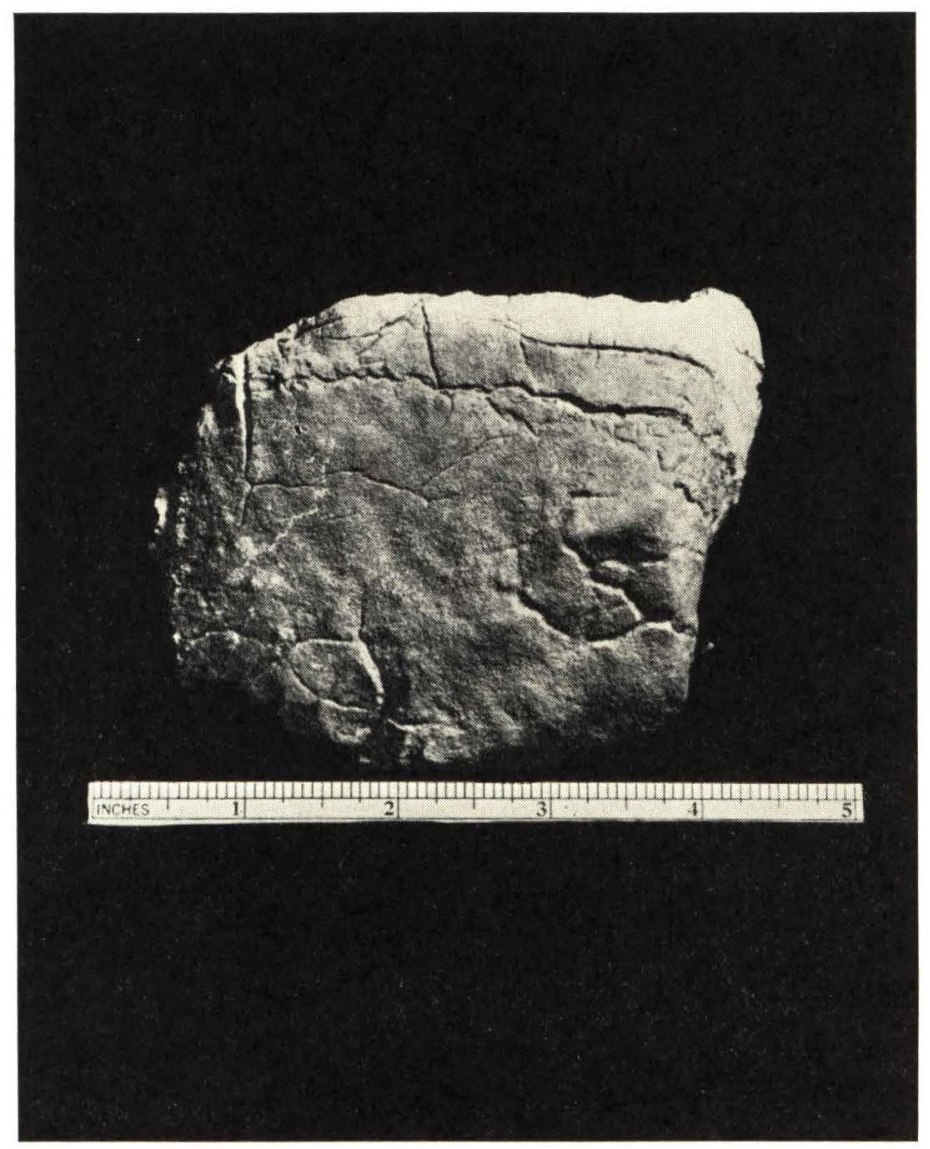

FIG. I6.-Upper surface of limestone fragment showing etching by rills controlled by fracture pattern.

of the structural pattern may be traced to the lower surface where, however, they are not so broadly opened. Figure I7 shows a fragment the exposed surface of which is fretted and pitted. The coating of secondary calcite is very thin. This fragment occurred on a steeper slope than the typical faceted forms. Although the lime was being 
removed irregularly, it was, nevertheless, flattening the face. The pitting seems attributable in part at least to lack of homogeneity in the limestone.

In solution-faceting the agent is freely falling rain. In the Grand Canyon instance wind erosion does not seem important, judging from the experience of many weeks of field work on and about the Tonto Platform during various seasons. The consideration of this

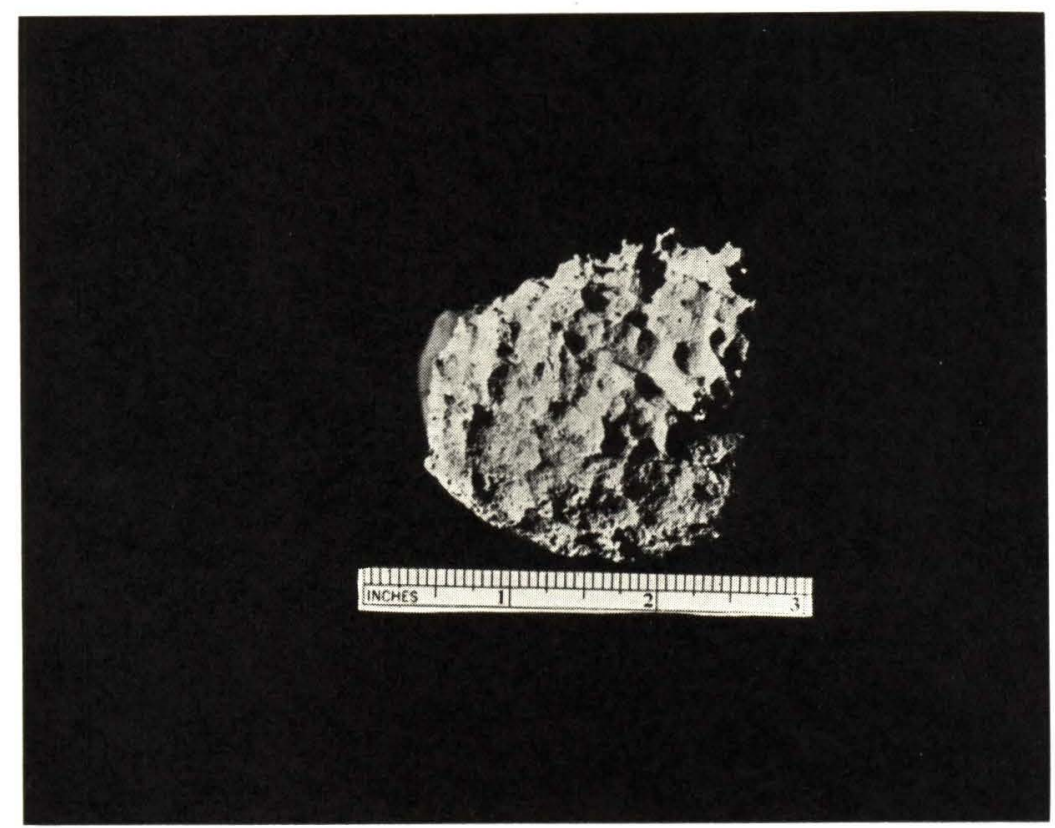

FIG. I7.- Solution-fretted upper surface of limestone fragment from steep slope

case may be useful in evaluation of the role of solution in a region where wind erosion is dominant.

RATE OF SOLUTION-FACETING

The surface of the Tonto Platform on which solution-faceted limestone fragments are found is young geologically and subject to frequent disturbance. It suggests that solution-faceting may be relatively rapid in some cases and, therefore, does not in itself testify to the antiquity of an erosion surface. Bryan, in estimating age significance, stated: 
In default of local data an estimate of the rate at which solution of the pebbles takes place seems impossible, but we can be certain that the formation of a facet which involves the loss of an inch of limestone required hundreds of years. .... A surface paved by solution-facetted pebbles doubtless has, however, an antiquity of at least two or more thousands of years. ${ }^{19}$

The Tonto Platform has an arid climate, with considerably less than the $I_{7}$ inches average annual rainfall of the south rim. But it is occasionally visited by local cloudbursts or heavy showers. Judging from observation through about five seasons, the writer believes that each part of the surface is visited by sufficiently heavy rains to disturb the surface and move fragments of cobble size within a few tens of years. On the basis of such physiographic evidence the writer believes that solution facets are formed in less than one hundred years on the Tonto Platform. It is likely that the limestone most frequently faceted here is considerably more porous and more rapidly soluble than in the cases discussed by Bryan. Care must therefore be exercised in ascribing antiquity to a surface containing solution-faceted limestone fragments.

\section{COMBINATION OF SOLUTION WITH ABRASION}

Limestone surfaces with patterns of arabesque design are found in different types of physiographic environment. Vermiculated cobbles found on a broad mesa below the mouth of the Virgin River in southern Nevada were figured by Gilbert and ascribed to carving by wind-blown sand. ${ }^{20}$ Here the conditions are arid. Fleury has discussed in considerable detail arabesque limestones found in the limestone coastal areas of Portugal. ${ }^{21}$ The phenomenon here is believed to be transitional between types found in desert regions and in the Alps. Fleury terms the feature "guillochage," literally "engine-turning," because of the complicated microsculptures. He discovered that the microsculptures do not pre-exist in the rock but are developed by erosional processes in some cases more or less influenced by petrographic factors. Corrasion by sandblast does not explain the features or their occurrence in Alpine regions. The fineness and the irregularity of the grooves in vermiculated types are

\footnotetext{
${ }^{19}$ Ibid., pp. $207-8$.

${ }^{20}$ Op. cit., p. 83 , Pl. IX. $\quad{ }^{21}$ Op. cit., pp. $\mathrm{II}^{-25}$.
} 
opposed to solution by water in simple runoff. Fleury describes the formation of vermiculations:

In "guillochage" the water does not work as it does either in streams or in lapiesation; it avoids gravity, while it is agitated under the influence of wind currents which drive it forward from the point where it strikes the rocks. It is generally in the state of drops, and it is provided generally by the dew and by the condensation of vapor or of mists as well as from rain; its mass is very small and without true mechanical action. The solution is also directed at times by the control of the wind, by the details of the shape (or the rock), and by the petrographic factors, that is to say, by conditions narrowly dependent on one another, which are able to explain, directly or by their variations, all the forms of microsculptures, as, for example, the radiating position of the holes, the regularity of the vermiculations apparently directed by the slope, and, above all, the differentiation of the decorations on the same rock or on a single small surface. $^{22}$

Fleury notes that, although solution is the principal process in erosion of the vermiculations, they may be modified by corrasion.

Figure 18 illustrates a stone of the type figured by Gilbert whereon the pattern is anastomosing. The cobble illustrated shows some variation in composition along bedding planes, yet the corrugations are not influenced thereby. The pattern reminds one of that produced by a film of water blowing over an automobile windshield during a light rain. The effect may be produced by concentrations of water, resulting from turbulence in the wind, with attendant solution along the surface. Once initiated, such a pattern might be perpetuated or accentuated by succeeding windy rainstorms. At the Death Valley locality rillensteine with streamlike pattern may be found. These are evidently formed, as suggested by Laudermilk and Woodford, by solution in streamlets flowing down the sides. ${ }^{23}$ Some deflections of the streamlets, as the result of the wind, is shown in Figure 19. Laudermilk and Woodford also point out that the vermiculations and rills may be more or less completely smoothed out by sand abrasion. The concept that the rills are formed at one time and partially obliterated at a later time is suggested by Blackwelder.

${ }^{22}$ Translated by Kirk Bryan.

${ }^{23}$ J. D. Laudermilk and A. O. Woodford, "Concerning Rillensteine," Amer. Jour. Sci., Vol. XXIII (5th ser.; 1932), pp. 135-54. 


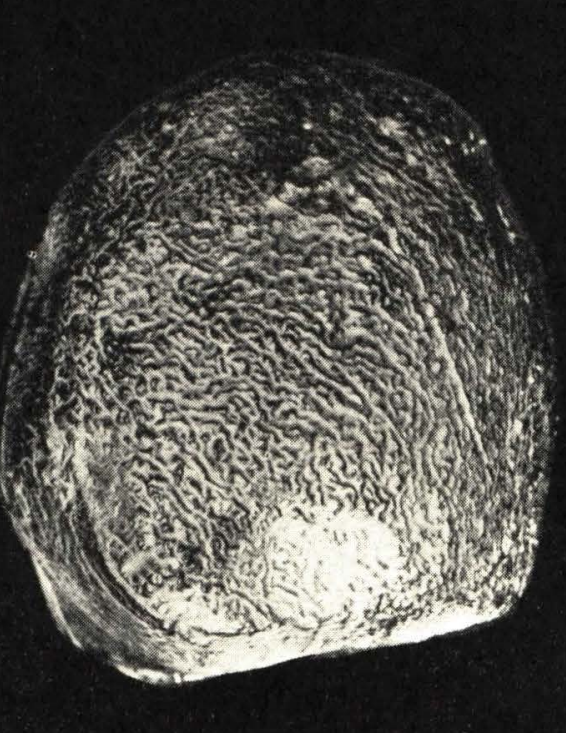

Fig. I8.-Solution pattern developed on smoothly rounded upper surface of a rather homogeneous limestone cobble. Death Valley, California.

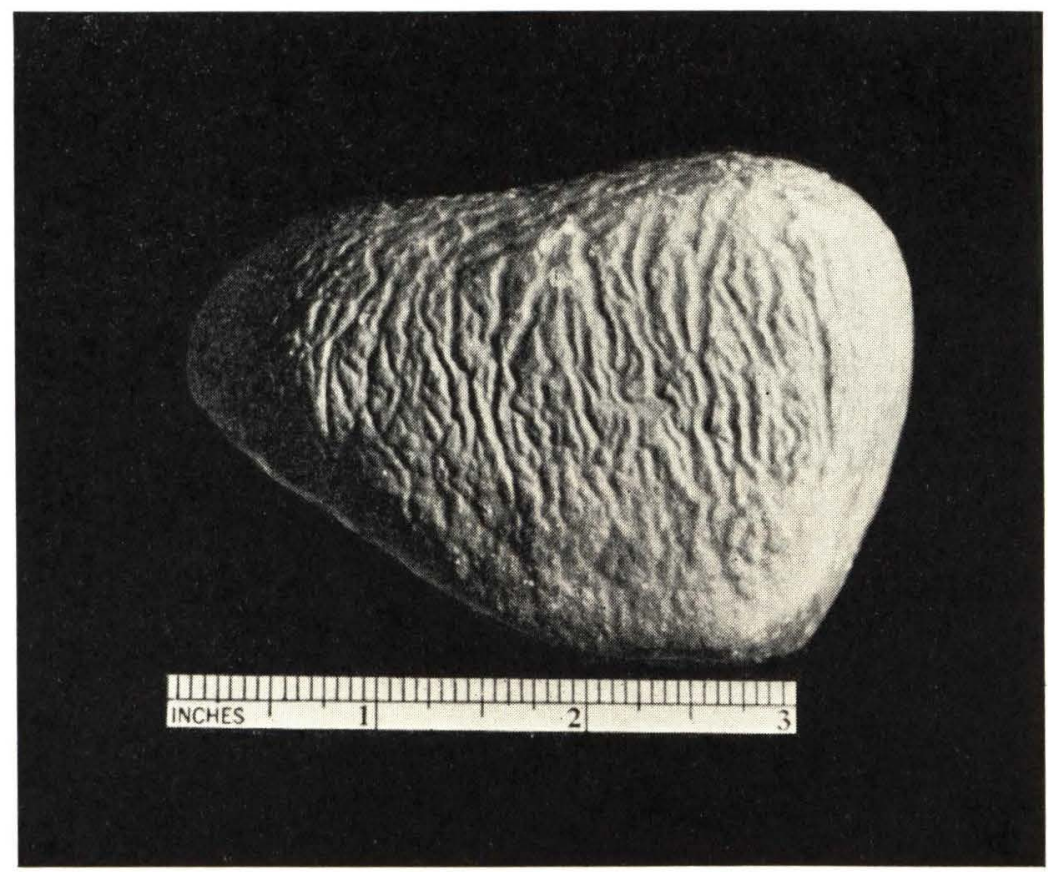

FIG. 19.- Streamlike rillensteine with rills showing deflection from the top toward the left in response to the prevailing wind. Surface which was below soil unrilled. Death Valley, California. 
Some of the crooked grooves which Eklaw and I have ascribed to solution, are limited to one or two sides of the pebbles. On the other side, which was more exposed to the sandblast, they have probably been erased. It seems to me

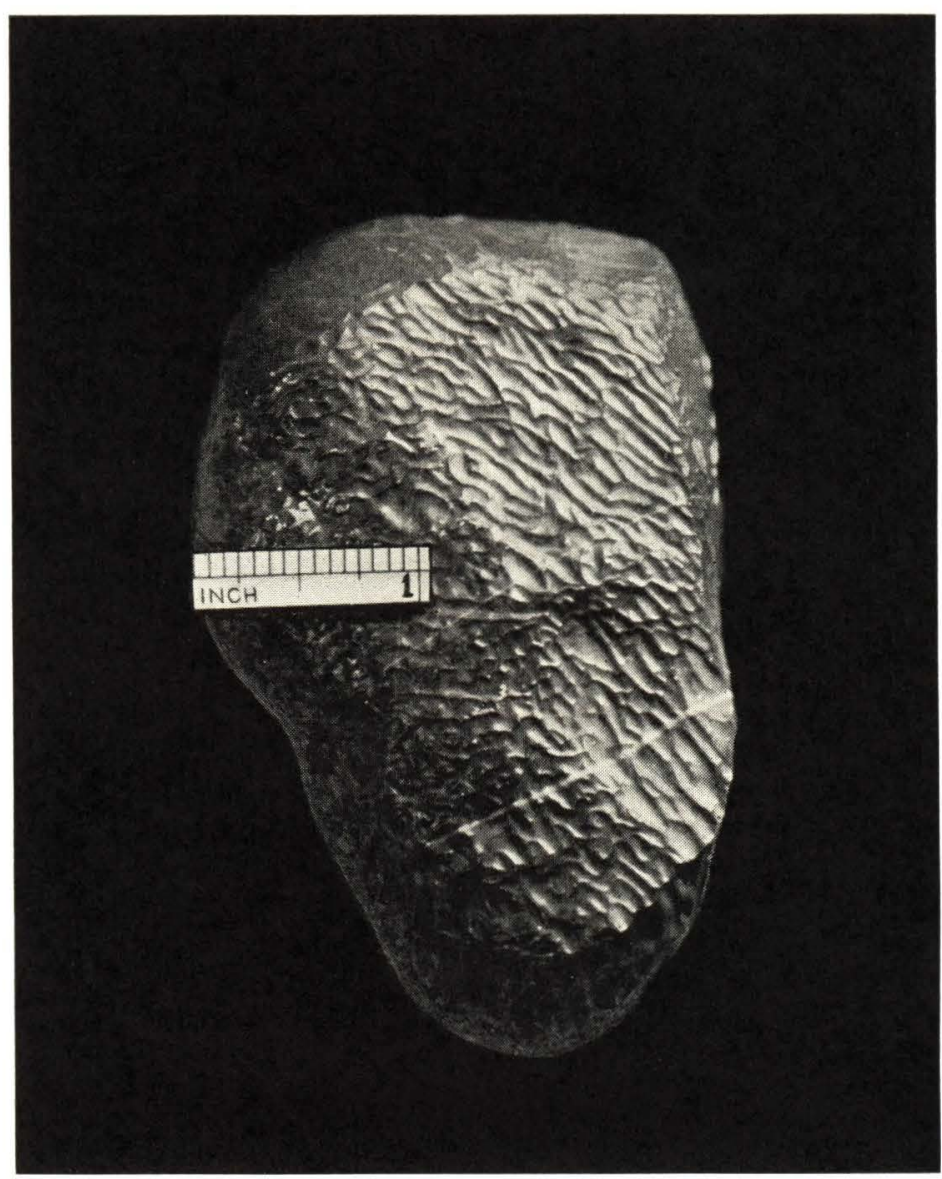

FIG. 20.-Cobble showing combination of fluting and anastomosing rilling on hori. zontal facet; truncation, deep fluting, and polishing on the windward face (lower right); and faint rilling and polishing on the lee.

possible that these stones preserve a record of climatic changes, - the rilled surface being made in somewhat moister epochs, and the sandblast facets being made in the dryer and perhaps windier times intervening. ${ }^{24}$

${ }^{24}$ Eliot Blackwelder, quoted by Laudermilk and Woodford, op. cit., pp. I $46-47$. 
It has been noted earlier in the discussion that the phenomena of faceting, polishing, fluting, and rilling are all found under similar conditions at the one locality in Death Valley. It is the opinion of the writer that separate epochs of solutional and abrasional activity are not required. The processes forming these features are all operative at the present time. The forms are often found in combination.

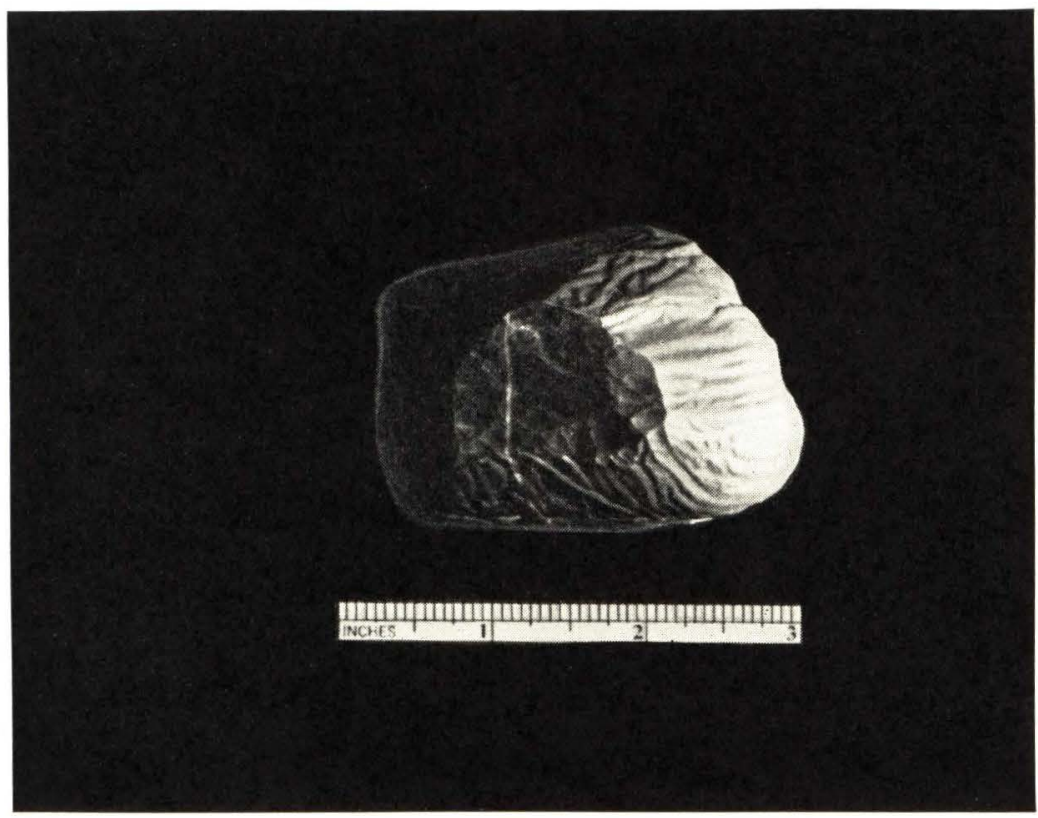

FIG. 2r.-Top view of limestone cobble showing smoothly polished and cut windward face $(l e f t)$; fluted top or horizontal facet; and polished rills on lee side. Death Valley, California. Specimen presented by H. D. Curry.

Small limestone chips lying flush with the ground level resemble solution-faceted chips but have an irregular pattern of low ridges and hollows. Facets of ridge-shaped ventifacts disturbed in orientation have a polished rugose surface. Figure 20 illustrates a limestone cobble whose horizontal facet has a pattern of wind flutes in part and anastomosing rills in part, suggesting concurrent solution and abrasion of the surface. The windward facet is polished smoothly 
for the most part but locally is fluted and is encroaching on earlier established flutes of the horizontal facet. This merely indicates that the direct sandblast erosion is much more rapid than the erosion of the flutes by vortices. Figure 7 shows a pebble on which wellmarked wind flutes may be seen on the horizontal facet. The smoothly polished windward face has been reduced more than a

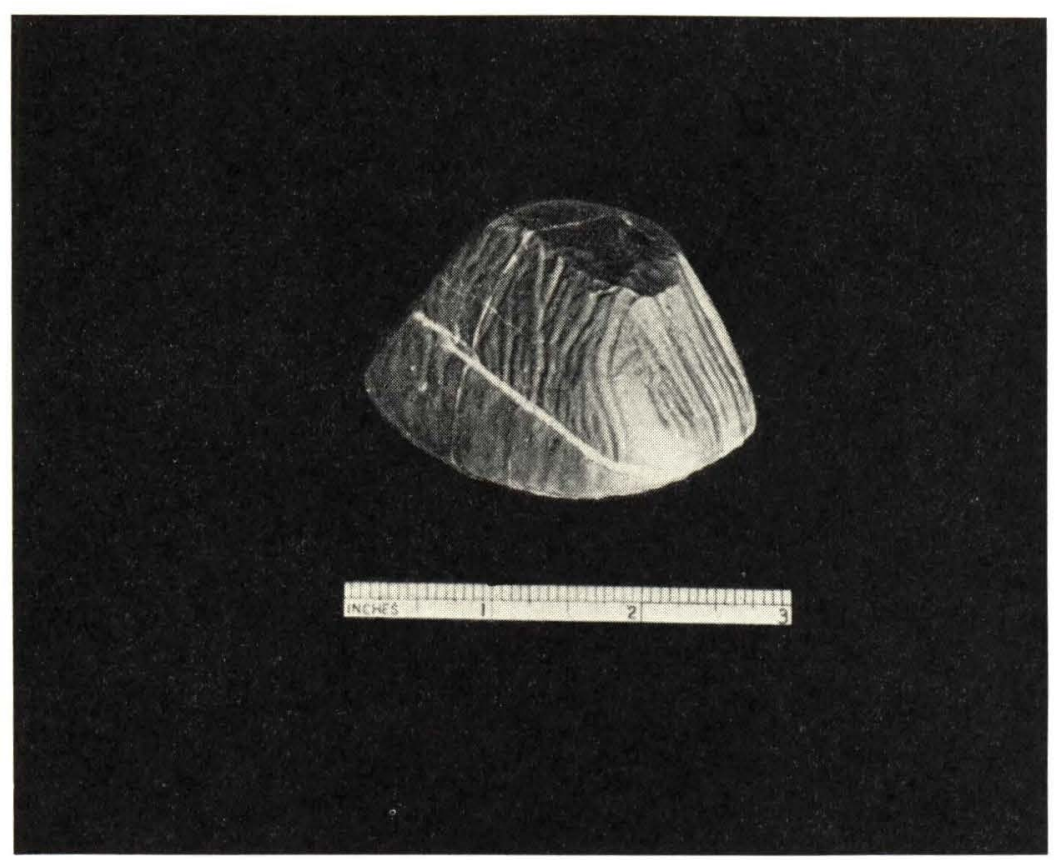

FIG. 22.-View of side and back of cobble shown in Fig. 20. Shallow fluting is visible on the horizontal facet. The broad and polished rills of the side appear to be deflected in the direction of wind flow, from left to right.

quarter of an inch as shown by a siliceous projection (hidden in the photograph). All features are shown on the cobble illustrated in Figures 2I and 22. There is a smoothly polished windward facet, a fluted horizontal facet, and extensive rilling down the sides deflected leeward and down the lee face. Some of the flutes are sources of rills. Although shallow and polished, it might be expected that they would be entirely obliterated by the rapid abrasion if they were 
not occasionally renewed by solution. Thus it is shown that solution is an important subsidiary process in faceting of limestone fragments, even under conditions of extreme aridity.

Acknowledgments.--The field work in the Grand Canyon district was carried out in conjunction with studies of the Archean rocks, a geological project, supported by the Carnegie Institution of Washington. The field work in the Death Valley region was supported by a grant from research funds by the California Institute of Technology. The writer wishes to thank Professor Kirk Bryan for many valuable suggestions and for criticism of the manuscript. 